\title{
Characterization of Infraspinatus Tendon Anatomy: The Soft-Tissue Portion of Remplissage
}

\author{
Thomas J. Kremen Jr., M.D., Carl-Henri Monfiston, M.S., John M. Garlich, M.D., \\ Milton T. M. Little, M.D., and Melodie F. Metzger, Ph.D.
}

\begin{abstract}
Purpose: To characterize the morphology of the infraspinatus (IS) tendon and evaluate the bony anatomy of the humeral head $(\mathrm{HH})$ to determine if there is a correlation between $\mathrm{HH}$ measurements and the amount of available IS tendon. Methods: The superior-inferior width as well as the medial-lateral (M-L) length of the inferior and superior portions of the IS tendon were measured in 15 human cadaveric shoulders. Three measurements were then obtained for each corresponding humeral head: (1) anterior to posterior (A-P) distance, (2) midcoronal humeral head distance (MCHH), and (3) M-L distance. Pearson correlation coefficients $(R)$ of tendon measurements relative to $\mathrm{HH}$ measurements were determined. Results: The mean \pm SD HH measurements were $44.3 \pm 3.3 \mathrm{~mm}$ for A-P, $49.3 \pm 3.4 \mathrm{~mm}$ at the MCHH, and $52.2 \pm 3.4 \mathrm{~mm}$ in the M-L plane. The mean M-L length of the superior portion of the IS tendon was significantly different from the inferior portion $(42.4 \mathrm{vs} 31.0 \mathrm{~mm}, P<.0001)$. The mean \pm SD width of the IS tendon was $19.4 \pm 3.0 \mathrm{~mm}$. There was a statistically significant correlation $(R=0.58)$ between the M-L length of the superior IS tendon relative to the M-L $\mathrm{HH}$ distance $(P<.05)$ and the $\mathrm{A}-\mathrm{P} \mathrm{HH}$ distance $(P<.05)$. Conclusions: The superior $\mathrm{M}-\mathrm{L}$ IS tendon length was significantly greater than the inferior M-L length. The M-L HH and the AP HH distances were significantly correlated to the M-L length of the superior portion of the IS tendon. These relationships may provide an estimation of the length of available IS tendon to help guide the management of Hill-Sachs lesions (HSLs). Clinical Relevance: Knowledge of the available IS length can help optimize the management of HSLs following anterior shoulder dislocation. If IS tendon M-L length is less than HSL M-L length, then remplissage may result in capsulomyodesis rather than tenodesis. Placement of the superior anchor in a position that is as superior as possible within the HSL defect will maximize the opportunity for IS tenodesis.
\end{abstract}

I njuries to the posterior humeral head are a common sequela associated with traumatic anterior shoulder

From the Department of Orthopaedic Surgery, David Geffen School of Medicine at UCLA, Los Angeles, California, U.S.A. (T.J.K.); Howard University College of Medicine, Washington, D.C., U.S.A. (C.-H.M.); Department of Orthopaedics, Cedars Sinai Medical Center, Los Angeles, California, U.S.A. (J.M.G., M.T.M.L., M.F.M.); and Cedars-Sinai Orthopaedic Biomechanics Laboratory, Los Angeles, California, U.S.A. (M.F.M.).

The authors report the following potential conflicts of interest or sources of funding: Research support for Thomas J. Kremen Jr. is provided by US Department of Veterans Affairs project 2020-000059. Full ICMJE author disclosure forms are available for this article online, as supplementary material.

Received August 29, 2020; accepted January 21, 2021

Address correspondence to Thomas J. Kremen Jr., M.D., Department of Orthopaedic Surgery, David Geffen School of Medicine at UCLA, 1225 15th Street, Suite 2100, Santa Monica, CA 90404,U.S.A. E-mail: tjkremen@ mednet.ucla.edu

Published by Elsevier Inc. on behalf of the Arthroscopy Association of North America. This is an open access article under the CC BY-NC-ND license (http://creativecommons.org/licenses/by-nc-nd/4.0/).

2666-061X/201476

https://doi.org/10.1016/j.asmr.2021.01.013 instability. These impaction fractures have been identified in $47 \%$ of individuals with a first-time glenohumeral dislocation and greater than $80 \%$ of patients experiencing recurrent anterior instability. ${ }^{1,2}$ This bony pathology, referred to as a Hill-Sachs lesion (HSL), ${ }^{3}$ is recognized as a significant risk factor for recurrent anterior shoulder instability even after arthroscopic repair of a Bankart lesion as this anatomic deformity can create an articular length mismatch between the humeral head and glenoid. ${ }^{4-6}$ The remplissage procedure was developed to counteract this bony mismatch by fixing the posterior superior rotator cuff tissue and capsule within the HSL to fill the humeral head defect with soft tissue. This effectively establishes a soft-tissue bumper to help prevent bony engagement of the humeral head on the glenoid. ${ }^{1,7}$

Biomechanical studies have demonstrated that HSLs involving $30 \%$ of the humeral head can lead to humeral head engagement on the glenoid, even after Bankart repair, and that remplissage procedures are capable of significantly decreasing the risk of subsequent instability among patients with clinically 
significant HSLs (i.e., those involving $20 \%$ to $40 \%$ of humeral head volume) and subcritical $(<20 \%)$ glenoid bone loss. ${ }^{1,2,8-11}$ Furthermore, with the introduction of the "glenoid track" concept, there is increased attention directed at quantifying the relevant size of HSLs in the setting of recurrent instability. ${ }^{12-14}$ While HSL morphology and boney changes have been characterized to help guide treatment approaches, characterization of the available infraspinatus (IS) tendon tissue for remplissage procedures has received little to no attention. Although others have recognized that remplissage often involves capsulodesis and/or capsulomyodesis in addition to tenodesis, ${ }^{2,7}$ assessments of IS tendon anatomy relative to measurable humeral head anatomic parameters have not been described. The size of an HSL and the humeral head ( $\mathrm{HH}$ ) can be easily measured with advanced imaging, but assessing tendon length is more challenging. For example, Saito et al. ${ }^{15}$ noted that the medial-lateral (M-L) length of HSLs can be greater than $30 \mathrm{~mm}$, yet estimates of M-L IS tendon length have not been reported. Thus, knowledge of IS tendon measurements relative to the HH may assist surgeons with estimating IS tendon length and preoperative planning. In addition, while rotator cuff tendon repairs to bone heal with predictable success, ${ }^{16,17}$ the results of direct IS musculotendinous junction tear repairs to bone have been reported as poor. ${ }^{18}$ Knowledge of IS tendon anatomy therefore warrants further attention. The purpose of this study was to characterize the morphology of the IS tendon and evaluate the bony anatomy of the $\mathrm{HH}$ to determine if there is a correlation between $\mathrm{HH}$ measurements and the amount of available IS tendon. We hypothesized that there is a significant correlation between $\mathrm{HH}$ measurements and the length of the IS tendon in the M-L plane.

\section{Methods}

Institutional review board approval was not required for this laboratory investigation using deidentified cadaveric specimens. Fifteen (13 male, 2 female) freshfrozen human cadaveric forequarters with a mean \pm SD age of $52.5 \pm 13.9$ years (range, 22-70 years) were procured from an institutionally approved tissue bank. Specimens were amputated at the level of the scapulothoracic joint and the sternoclavicular joint proximally and at the level of the midhumerus distally. All specimens were carefully inspected to confirm that the rotator cuff, glenoid, and humeral head structures were all intact with no indication of significant shoulder pathology or prior shoulder surgery. Specimens were stored at $-30^{\circ} \mathrm{C}$ and thawed overnight at room temperature prior to dissection. Dissections were performed by T.J.K., C.H.M., and J.G. Measurements were obtained by C.H.M. and J.G.

\section{Rotator Cuff Measurements}

Once fully thawed, the scapular spine was identified delineating the interval between the medial supraspinatus and infraspinatus musculotendinous units. This interval was extended laterally in line with the fibers of these structures until the footprint of these tendon insertions on the humeral head greater tuberosity was identified. Next, the interval between teres minor and IS muscle bellies, as well as the quadrangular space, was identified. The interval between the teres minor and IS was divided medially and extended laterally in line with the corresponding muscle and tendon fibers until the footprint was encountered as stated above (Fig $1 \mathrm{~A}$ and B). Once the infraspinatus muscle belly was released from its scapular attachments, excellent exposure of the undersurface of the tendon (articular side) was possible, making the posterior humeral head and its "bare area" readily identifiable (Fig 2). The IS tendon was measured along its superior-inferior width and its M-L length. Gross differences in M-L length were noted when comparing the superior and inferior portions of the IS tendon; therefore, the superior and inferior M$\mathrm{L}$ lengths were measured and recorded independently.

\section{Humeral Head Measurements}

After obtaining measurements of the infraspinatus tendon, the humeral head was released from its capsuloligamentous attachments to the glenoid, and measurements of each humeral head were obtained in the axial and coronal planes of each specimen (Fig 3). In the axial plane, the maximum value for anteriorposterior (A-P) distance was recorded. In the coronal plane, the midcoronal humeral head superior-inferior distance was recorded as well as the maximum value for M-L humeral head distance spanning from the most medial portion of the articular surface to the lateral cortex of the humerus. These anatomic landmarks were used as representative of anatomic landmarks because they could also be adequately assessed on preoperative advanced imaging studies.

\section{Statistical Analysis}

Descriptive statistics and Pearson correlation coefficients of tendon measurements relative to humeral head measurements were calculated using GraphPad Prism 7 software (GraphPad Software, La Jolla, CA) with significance set at $P<.05$. Line of best fit was calculated from a linear regression analysis of our data and used to generate a predictive model of superior IS tendon $\mathrm{M}$-L length relative to each humeral head anatomic measurement (midcoronal humeral head, $\mathrm{M}$ L, and A-P; Fig 3). Given that HSLs typically affect the posterior-superior portion of the humeral head, the superior portion of the IS tendon was deemed to be 
Fig 1. (A, B) Posterior view of bursal surface of rotator cuff during dissection demonstrating the infraspinatus muscle (ISm), infraspinatus tendon (ISt), teres minor muscle (TMm), and teres minor tendon (TMt) as well as the interval between infraspinatus and teres minor tendons (black arrows).
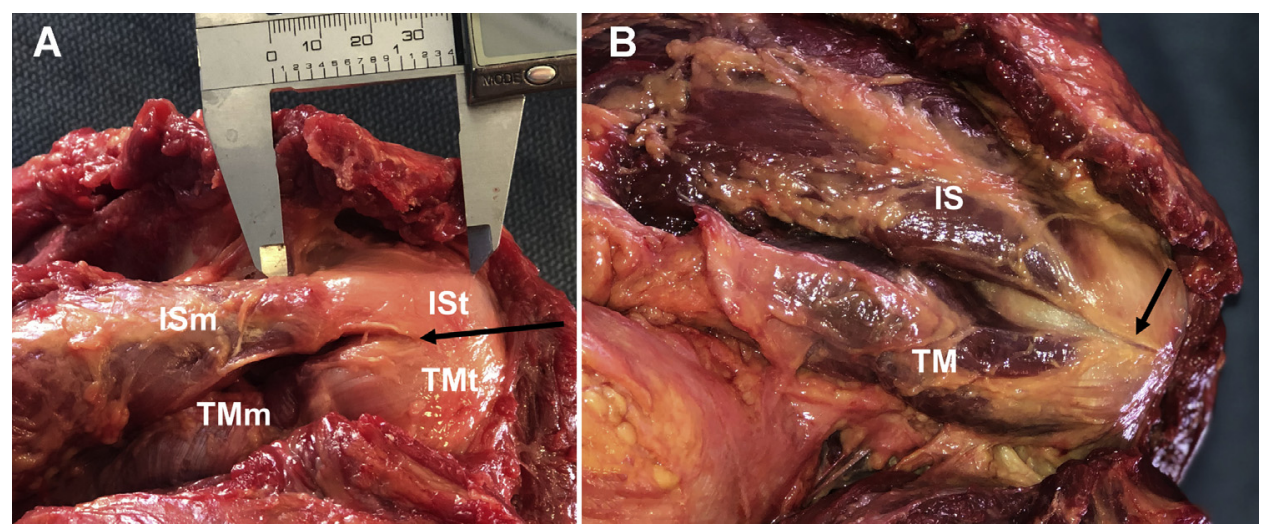

most relevant in the setting of planned remplissage procedures.

\section{Results}

\section{Infraspinatus Tendon Measurements}

Mean \pm SD measurement of the superior portion of the infraspinatus tendon in the M-L plane was $42.4 \pm$ $5.5 \mathrm{~mm}$, and the mean $\pm \mathrm{SD}$ inferior $\mathrm{M}-\mathrm{L}$ tendon length was $31.0 \pm 4.7 \mathrm{~mm}$ (Table 1). The superior $\mathrm{M}-\mathrm{L}$ length of the infraspinatus tendon was significantly greater than the inferior M-L length by an average of $11.4 \pm 6.5 \mathrm{~mm}(95 \%$ confidence interval, 7.9-15.0 mm; $P<.0001$; Fig 4). The mean $\pm \mathrm{SD}$ superior-inferior width of the IS tendon was $19.4 \pm 3.0 \mathrm{~mm}$ and was significantly positively correlated to specimen age $(P<$ $.05, R=0.57)$. The M-L length of the superior aspect of the IS tendon was significantly correlated with both the M-L humeral head distance $(R=0.56, P=.03$; Fig 5$)$ and the anterior-posterior humeral head distance $(R=$ $0.58, P=.02$; Fig 6$)$. The M-L length of the superior portion of the IS tendon was only marginally correlated to the superior-inferior humeral neck length (anatomic neck, $R=0.48, P=.07$; Fig 7 ). The length of the inferior portion of the medial-lateral IS tendon was not correlated to any of the three measurements of the humeral head evaluated.

Although quantification of teres minor tendon M-L length was not performed in this study, the qualitatively short M-L length of the teres minor tendon (Fig 4B) relative to the IS tendon was consistently observed among all of our specimens.

\section{Humeral Head Measurements}

All data are presented as mean \pm SD unless otherwise noted. The average A-P diameter of the humeral head was $44.3 \pm 3.3 \mathrm{~mm}$ (Table 1). The average superiorinferior humeral neck diameter was $49.3 \pm 3.4 \mathrm{~mm}$, and the average M-L diameter of the humeral head measured $52.2 \pm 3.4 \mathrm{~mm}$.
Two methods estimating the M-L length of the superior IS tendon were developed based on best-fit calculations between the A-P and M-L humeral head measurements.

Method 1: Superior IS length $(\mathrm{mm})=0.969 *(\mathrm{~A}-\mathrm{P}$ $\mathrm{HH}$ measurement, $\mathrm{mm})-0.503$.

Method 2: Superior IS length $=0.923 *(\mathrm{M}-\mathrm{L}$ HH measurement, $\mathrm{mm})-5.762$.

\section{Discussion}

A significant positive correlation was identified between both the A-P and M-L humeral head measurements relative to the M-L length of superior portion of the IS tendon. In addition, there was a significant difference between the superior and inferior portions of the IS tendon, with the superior portion having a greater M-L length (Figs 2,4).

Clinically significant humeral head defects in the absence of glenoid bone loss can be treated several ways, including remplissage, glenoid augmentation,

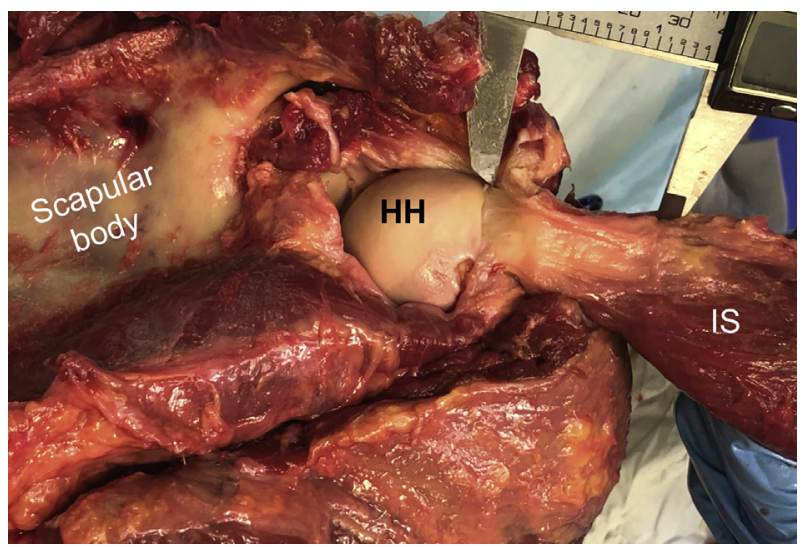

Fig 2. Reflected infraspinatus (IS) muscle and tendon demonstrating the articular surface of the infraspinatus tendon, which was used for measurements in this study. The humeral head $(\mathrm{HH})$ and scapular body are easily visualized. Digital calipers are located at the superior portion of the infraspinatus tendon. 


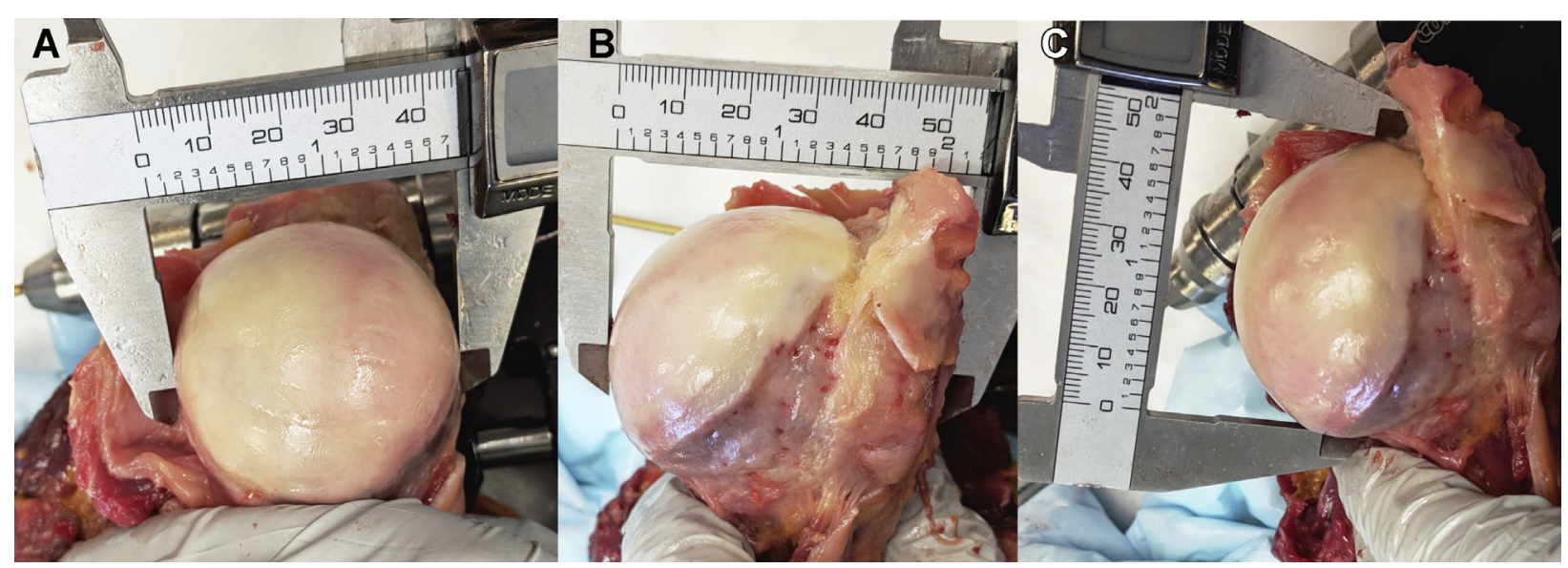

Fig 3. Gross anatomic images depicting (A) anterior-posterior humeral head distance, (B) medial-lateral humeral head distance, and $(\mathrm{C})$ superior-inferior mid-coronal humeral head measurements.

and humeral head augmentation with an allograft, a partial arthroplasty prosthesis, or a complete humeral head arthroplasty. While it is generally agreed that a $20 \%$ to $40 \%$ humeral head defect is clinically significant, the specific treatment approach for patients with these lesions is less clear, despite our contemporary understanding of the "glenond track" concept. ${ }^{8,19}$ Several questions remain regarding the optimal strategy to address the humeral side of a mismatch between the arc of the glenoid and the boney morphology of the humeral head. Furthermore, while quantifying the size of an HSL to help guide management of glenoid bone defects has recently received heightened attention with the evolution of the "glenoid track" concept, ${ }^{12-14}$ the soft-tissue portion of the remplissage procedure has received little to no attention. Thus, the data presented in the present study provide a greater understanding of shoulder anatomy and will likely contribute to preoperative planning and appropriate execution of remplissage procedures.

Our results demonstrate that the superior portion of the IS tendon is significantly longer along its M-L length compared with the inferior portion of the IS tendon (Fig 4). Mochizuki et al. ${ }^{20}$ reported similar findings in their analysis of the infraspinatus footprint at the humerus, corroborating our measurements. This difference can be particularly important when selecting the location of anchor placement within the HSL during remplissage

Table 1. Cadaveric Specimen Demographics and Measurements

\begin{tabular}{|c|c|c|c|c|c|c|c|c|c|}
\hline Age, y & Sex & Laterality & Race & $\begin{array}{l}\text { Superior }(\mathrm{M}-\mathrm{L}) \\
\text { Length, mm }\end{array}$ & $\begin{array}{c}\text { Inferior }(\mathrm{M}-\mathrm{L}) \\
\text { Length, mm }\end{array}$ & $\begin{array}{c}\text { Superior- } \\
\text { Inferior } \\
\text { Width, mm } \\
\end{array}$ & $\begin{array}{l}\text { M-L Humeral } \\
\text { Head } \\
\text { Diameter, mm }\end{array}$ & $\begin{array}{c}\text { Midcoronal Humeral } \\
\text { Head } \\
\text { Diameter, mm }\end{array}$ & $\begin{array}{c}\text { A-P Humeral } \\
\text { Head, mm }\end{array}$ \\
\hline 54 & $\mathrm{~F}$ & RT & White & 33.6 & 26.1 & 21.1 & 48.6 & 46.1 & 42.2 \\
\hline 54 & $\mathrm{~F}$ & LT & White & 40.0 & 31.0 & 17.5 & 48.0 & 46.0 & 41.5 \\
\hline 36 & M & RT & White & 42.9 & 34.6 & 17.8 & 52.9 & 48.6 & 44.6 \\
\hline 36 & M & LT & White & 42.9 & 32.5 & 18.6 & 53.2 & 48.8 & 43.6 \\
\hline 44 & M & LT & White & 48.3 & 32.5 & 16.3 & 52.8 & 50.6 & 42.6 \\
\hline 22 & M & LT & White & 44.4 & 22.5 & 15.4 & 50.3 & 47.1 & 43.2 \\
\hline 64 & M & RT & White & 45.0 & 30.5 & 25.0 & 48.5 & 45.5 & 43.0 \\
\hline 64 & M & LT & White & 42.1 & 36.4 & 18.1 & 49.2 & 46.3 & 42.1 \\
\hline 70 & M & LT & White & 48.1 & 26.0 & 22.9 & 60.7 & 57.7 & 53.6 \\
\hline 59 & M & RT & $\begin{array}{l}\text { Black or } \\
\text { African } \\
\text { American }\end{array}$ & 50.8 & 39.0 & 24.6 & 55.4 & 51.1 & 48.5 \\
\hline 59 & M & LT & $\begin{array}{l}\text { Black or } \\
\text { African } \\
\text { American }\end{array}$ & 42.4 & 36.3 & 15.4 & 53.9 & 53.8 & 47.3 \\
\hline 67 & M & RT & White & 47.0 & 24.8 & 21.3 & 54.1 & 50.5 & 43.9 \\
\hline 67 & M & LT & White & 42.0 & 33.8 & 19.1 & 54.5 & 52.0 & 44.9 \\
\hline 46 & M & RT & White & 33.4 & 30.1 & 18.1 & 50.5 & 49.3 & 42.1 \\
\hline 46 & M & $\mathrm{LT}$ & White & 32.8 & 28.1 & 19.2 & 50.8 & 46.2 & 40.9 \\
\hline Mean & & & & 42.4 & 30.9 & 19.4 & 52.2 & 49.3 & 44.3 \\
\hline
\end{tabular}

AP, anterior-posterior; LT, left; M-L, medial-lateral; RT, right. 
Fig 4. (A) Graph demonstrating superior medial-lateral (M-L) length of the infraspinatus (IS) tendon significantly greater than the inferior $\mathrm{M}-\mathrm{L}$ length, $P<$ .0001 . (B) Gross image of infraspinatus tendon demonstrating difference in M-L length of the superior (blue asterisk) and inferior (black bracket) portions of the IS tendon. Of note, teres minor tendon M-L length (yellow arrow) is less than that of the IS tendon.
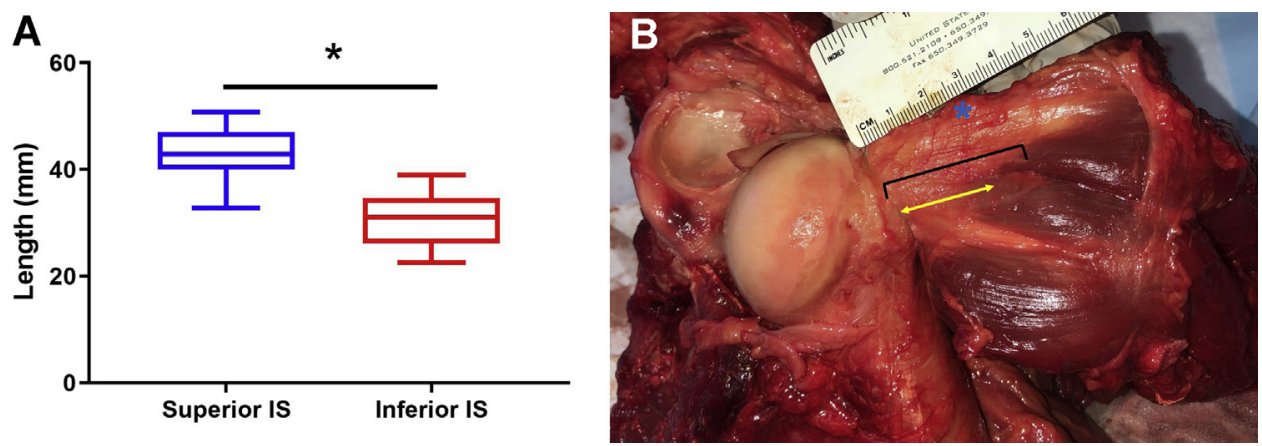

procedures. Since the superior portion of the IS tendon has a greater M-L length, placing the anchor as superior as possible within the HSL may increase the probability that the resultant remplissage construct will be a true IS tenodesis rather than a capsulomyodesis. Tenodesis is favorable because rotator cuff tendon repairs heal to bone with predictable success, ${ }^{16,17}$ whereas direct repair of infraspinatus musculotendinous junction tears is poor. ${ }^{18}$ Therefore, relying on the healing of an isolated capsulomyodesis of the infraspinatus, which is analogous to an infraspinatus musculotendinous junction tear repair, may be a contributing factor to the reported rate of recurrent instability after remplissage. ${ }^{21}$

Our observation that the inferior IS tendon has a shorter M-L length and the qualitative observation that the teres minor tendon also has a short M-L length supports findings reported by Ladermann et al. ${ }^{7}$ that demonstrate that sutures placed during simulated remplissage procedures are at risk of capturing a portion of the infraspinatus muscle and/or the teres minor muscle. IS muscle capture carries a risk of undesired complications such as shoulder pain or decreased IS muscle force production. A prospective study by Nourissat et al. $^{22}$ found one-third of patients with recurrent shoulder dislocations who underwent Bankart repair with remplissage had posterosuperior shoulder pain compared with patients with the Bankart repair alone. The IS musculotendinous unit is important for dynamic stabilization of the glenohumeral joint and appropriate establishment of the force couple in the axial plane. Only 2 muscles (teres minor and infraspinatus) generate external rotation forces on the humerus in the axial plane. These external rotators work in opposition to 4 muscles exerting internal rotation forces onto the proximal humerus (pectoralis major, latissimus dorsi, teres major, and subscapularis). The internal rotators have a much larger cross-sectional surface area, and inappropriate balance of this force couple can lead to glenohumeral joint dysfunction. ${ }^{23,24}$ Therefore, surgeons should avoid procedures that can jeopardize the external rotators, particularly in the setting of glenohumeral joint instability. Capture of the
IS muscle, as would occur when the HSL M-L length is greater than the available IS tendon M-L length, could possibly contribute to infraspinatus muscle injury and subsequent dysfunction. An accurate estimate of the limits of infraspinatus tenodesis is therefore attractive to avoid potential IS muscle injury. Furthermore, as recognized by others, the potential for myodesis after remplissage procedures and any associated muscle damage may also contribute to the reported risk of recurrent instability after remplissage procedures as well as the reported postoperative range-of-motion limitations. ${ }^{7}$ The impact of these concerns is largely unknown and requires further investigation.

Saito et al. ${ }^{15}$ measured the HSL of 34 patients and recorded the depth of the HSL, the M-L distance between the greater tuberosity (IS insertion), and the medial edge of HSL. The average depth was $5 \pm 4 \mathrm{~mm}$, and the average M-L distance between IS insertion and medial edge of HSL was $25 \pm 7 \mathrm{~mm}$, with multiple individual values greater than $30 \mathrm{~mm}$ even in their relatively small sample size. In our study, the M-L length of the inferior portion of IS tendon was $31 \mathrm{~mm}$, which, based on the data reported by Saito et al., ${ }^{15}$ would result in a clinically significant mismatch of $\mathrm{M}$ -

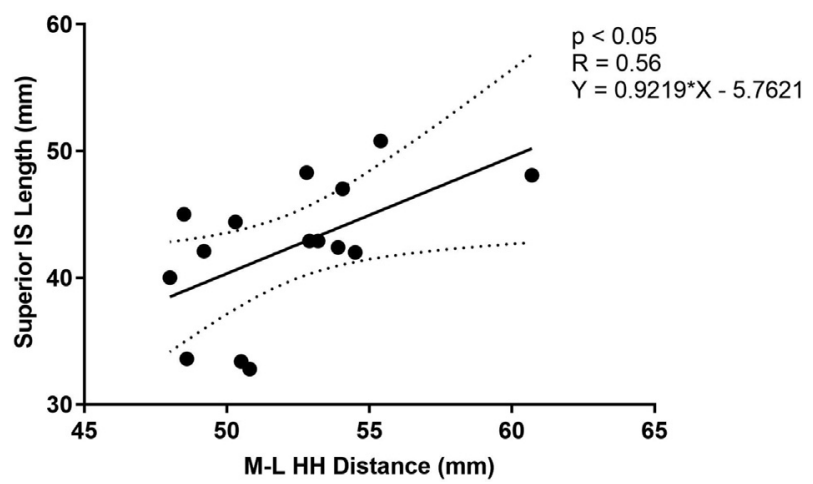

Fig 5. Scatterplot of the medial-lateral (M-L) length of the superior portion of the infraspinatus (IS) tendon (y-axis) relative to the $\mathrm{M}$ - $\mathrm{L}$ distance of the humeral head ( $\mathrm{HH}, \mathrm{x}$-axis). Dotted lines represent the upper and lower 95\% confidence interval of the linear regression line. 


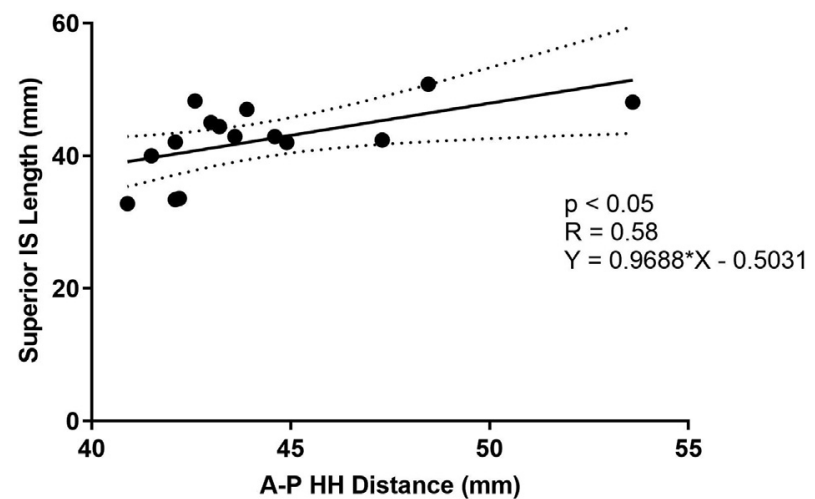

Fig 6. Scatterplot of the medial-lateral length of the superior portion of the infraspinatus (IS) tendon (y-axis) relative to the anterior-posterior (A-P) distance of the humeral head $(\mathrm{HH}, \mathrm{x}$ axis). Dotted lines represent the upper and lower 95\% confidence interval of the linear regression line.

L tendon length and HSL size among a proportion of patients. If a patient's HSL appears to be relatively large, then measuring the M-L HSL distance (as shown in Fig 8 ) and estimating superior IS tendon M-L length, using one of the methods described in the current study, may assist the surgeon in preoperative planning. Specifically, these data could be employed to help estimate how far medially suture anchors may be placed within an HSL to achieve a true IS tenodesis or perhaps lead surgeons to treat large HSLs with humeral head allografts rather than remplissage. However, it should be noted that the clinical application of our findings in such a manner would be premature as further prospective clinical investigations would certainly be needed before surgeons could reliably use this approach.

Although our work improves our understanding of IS tendon anatomy, there are still many unanswered questions regarding the remplissage procedure. Currently, it is unknown how much tendon needs to be tenodesed within an HSL defect to effectively reduce the risk of recurrent instability. Varying degrees of glenoid bone loss further complicates this issue. It is also unknown how the depth of an HSL affects ideal anchor placement and filling of an HSL, which may affect anchor placement in the both the superior-inferior plane and the M-L plane. Finally, there may not be a clinically significant difference between a true tenodesis and a capsulomyodesis in the setting of a remplissage procedure. Although IS tendon pathology in the setting of anterior shoulder instability has been described previously $^{25}$ and the repair of infraspinatus musculotendinous junction tears is associated with poor outcomes, ${ }^{18}$ this may not translate to poor healing of capsulomyodesis procedures in patients with shoulder instability. Further prospective clinical investigations are needed to help clarify the clinical utility of the descriptive anatomic findings presented here.

\section{Limitations}

This study does have some noteworthy limitations. First, this is a cadaveric study of 15 mostly male specimens. Although shoulder instability is more common in male patients, our findings may not be broadly applicable to all patients. Relying on preoperative advanced imaging studies for measurements also has inherent limitations. One limitation is that image acquisition may be oriented in a plane of view that does not align with the patient's in vivo anatomy. Although measuring the distance between the IS tendon insertion on the HH and the medial edge of an HSL is relatively easy on axial magnetic resonance imaging or computed tomography images, measuring M-L length of the IS tendon on the same axial sequence or even arthroscopically is challenging and can result in discordant values. ${ }^{26}$ This apparent discrepancy is likely, at least in part, due to the known obliquity of the IS tendon at the posterior shoulder, which can be appreciated on any coronal magnetic resonance shoulder sequence. Due to this in vivo obliquity, the true ML-length of the superior IS tendon available to fill an HSL may be underestimated by the $2 \mathrm{HH}$ cadaver-based ex vivo estimation methods described in our current study. Our IS tendon $\mathrm{M}-\mathrm{L}$ length estimations were derived from measurements of the IS tendon that were made within the same plane (i.e., IS tissue released from its native attachments at the inferior scapula, which eliminated the normal in vivo IS tendon obliquity relative to the axis of the adducted humeral head). Our study also lacks quantification of the teres minor tendon relative to $\mathrm{HH}$ and IS tendon measurements. Others have indicated that teres minor tissue is likely captured during remplissage procedures $^{7}$; therefore, knowledge of teres minor estimated length would likely also contribute to preoperative planning. Last, the clinical significance of these data is unknown.

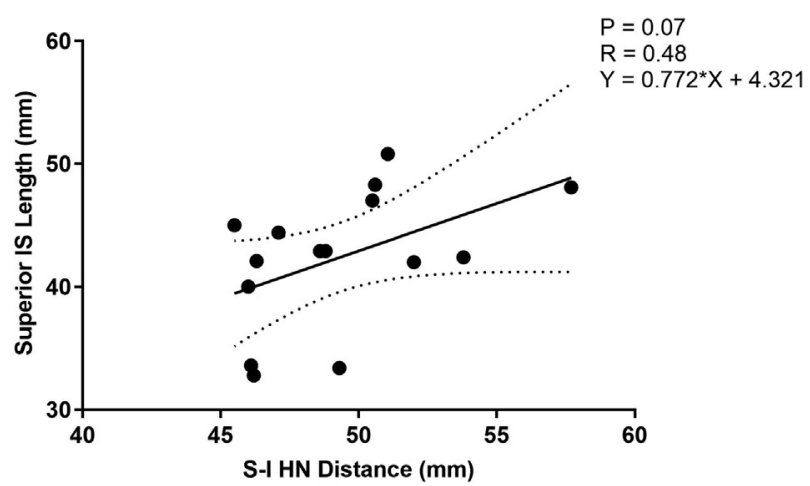

Fig 7. Scatterplot of the medial-lateral length of the superior portion of the infraspinatus (IS) tendon (y-axis) relative to the superior-inferior (S-I) humeral neck (HN; anatomic neck) distance (x-axis). Dotted lines represent the upper and lower $95 \%$ confidence interval of the linear regression line. 

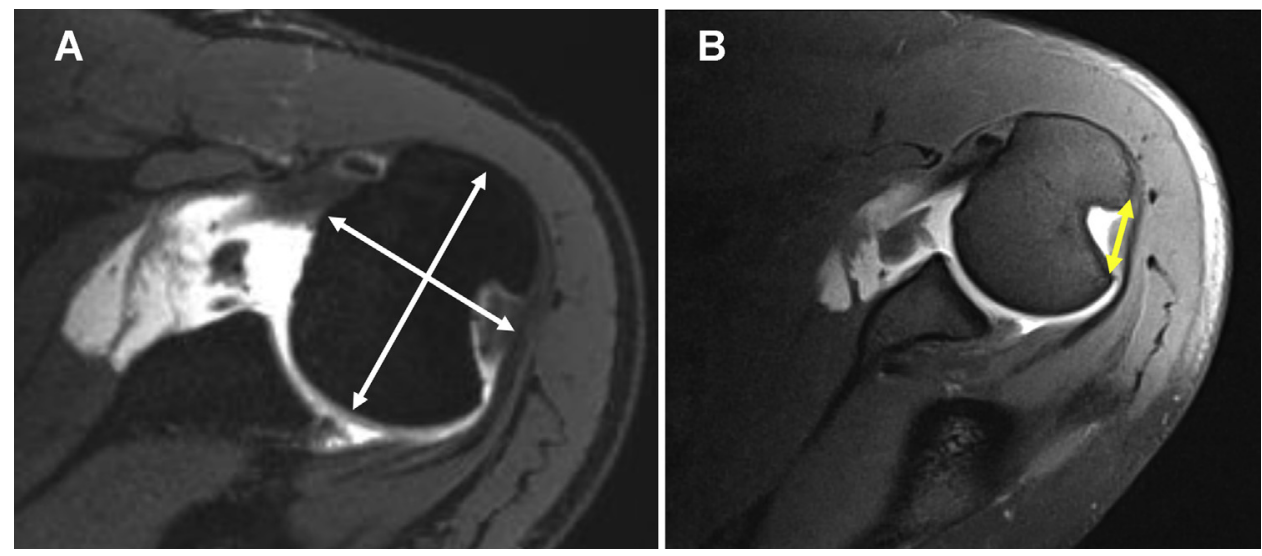

Fig 8. (A) Example of preoperative humeral head measurements on a 3 Telsa (3T) magnetic resonance imaging (MRI) axial image of the shoulder. (B) Example of preoperative Hill-Sachs lesion measurement on a 3T MRI axial image of the shoulder.

\section{Conclusions}

In conclusion, our results demonstrate that the superior M-L IS tendon length was significantly greater than the inferior M-L length. The M-L HH and the AP $\mathrm{HH}$ distances were significantly correlated to the M-L length of the superior portion of the IS tendon. These relationships may provide an estimation of the length of available IS tendon to help guide the management of HSLs.

\section{References}

1. Elkinson I, Giles JW, Faber KJ, et al. The effect of the remplissage procedure on shoulder stability and range of motion: An in vitro biomechanical assessment. J Bone Joint Surg Am 2012;94:1003-1012.

2. Boileau P, O'Shea K, Vargas P, Pinedo M, Old J, Zumstein M. Anatomical and functional results after arthroscopic Hill-Sachs remplissage. J Bone Joint Surg Am 2012;94:618-626.

3. Hill HA, Sachs MD. The grooved defect of the humeral head: A frequently unrecognized complication of dislocations of the shoulder joint. Radiology 1940;35:690-700.

4. Boileau P, Villalba M, Hery JY, Balg F, Ahrens P, Neyton L. Risk factors for recurrence of shoulder instability after arthroscopic Bankart repair. J Bone Joint Surg Am 2006:88:1755-1763.

5. Burkhart SS, Danaceau SM. Articular arc length mismatch as a cause of failed Bankart repair. Arthroscopy 2000; 16:740-744.

6. Kralinger FS, Golser K, Wischatta R, Wambacher M, Sperner G. Predicting recurrence after primary anterior shoulder dislocation. Am J Sports Med 2002;30:116-120.

7. Ladermann A, Arrigoni P, Barth J, et al. Is arthroscopic remplissage a tenodesis or capsulomyodesis? An anatomic study. Knee Surg Sports Traumatol Arthrosc 2016;24: 573-577.

8. Liu JN, Gowd AK, Garcia GH, Cvetanovich GL, Cabarcas BC, Verma NN. Recurrence rate of instability after remplissage for treatment of traumatic anterior shoulder instability: A systematic review in treatment of subcritical glenoid bone loss. Arthroscopy 2018;34: 2894-2907.e2892.

9. Franceschi F, Papalia R, Rizzello G, et al. Remplissage repair-new frontiers in the prevention of recurrent shoulder instability: A 2-year follow-up comparative study. Am J Sports Med 2012;40:2462-2469.

10. Bastard C, Herisson O, Gaillard J, Nourissat G. Impact of remplissage on global shoulder outcome: A long-term comparative study. Arthroscopy 2019;35:1362-1367.

11. Hartzler RU, Bui CN, Jeong WK, et al. Remplissage of an off-track Hill-Sachs lesion is necessary to restore biomechanical glenohumeral joint stability in a bipolar bone loss model. Arthroscopy 2016;32:2466-2476.

12. Di Giacomo G, Itoi E, Burkhart SS. Evolving concept of bipolar bone loss and the Hill-Sachs lesion: From "engaging/non-engaging" lesion to "on-track/off-track" lesion. Arthroscopy 2014;30:90-98.

13. Yamamoto $\mathrm{N}$, Itoi $\mathrm{E}$, Abe $\mathrm{H}$, et al. Contact between the glenoid and the humeral head in abduction, external rotation, and horizontal extension: A new concept of glenoid track. J Shoulder Elbow Surg 2007;16:649-656.

14. Shaha JS, Cook JB, Rowles DJ, Bottoni CR, Shaha SH, Tokish JM. Clinical validation of the glenoid track concept in anterior glenohumeral instability. J Bone Joint Surg Am 2016;98:1918-1923.

15. Saito H, Itoi E, Minagawa H, Yamamoto N, Tuoheti $Y$, Seki N. Location of the Hill-Sachs lesion in shoulders with recurrent anterior dislocation. Arch Orthop Trauma Surg 2009;129:1327-1334.

16. Slabaugh MA, Nho SJ, Grumet RC, et al. Does the literature confirm superior clinical results in radiographically healed rotator cuffs after rotator cuff repair? Arthroscopy 2010;26:393-403.

17. Mather RC III, Koenig L, Acevedo D, et al. The societal and economic value of rotator cuff repair. J Bone Joint Surg Am 2013;95:1993-2000.

18. Walch G, Nove-Josserand L, Liotard JP, Noel E. Musculotendinous infraspinatus ruptures: An overview. Orthop Traumatol Surg Res 2009;95:463-470.

19. Rashid MS, Crichton J, Butt U, Akimau PI, Charalambous CP. Arthroscopic "remplissage" for shoulder instability: A systematic review. Knee Surg Sports Traumatol Arthrosc 2016;24:578-584. 
20. Mochizuki T, Sugaya H, Uomizu M, et al. Humeral insertion of the supraspinatus and infraspinatus: New anatomical findings regarding the footprint of the rotator cuff. J Bone Joint Surg Am 2008;90:962-969.

21. Buza JA III, Iyengar JJ, Anakwenze OA, Ahmad CS, Levine WN. Arthroscopic Hill-Sachs remplissage: A systematic review. J Bone Joint Surg Am 2014;96:549-555.

22. Nourissat G, Kilinc AS, Werther JR, Doursounian L. A prospective, comparative, radiological, and clinical study of the influence of the "remplissage" procedure on shoulder range of motion after stabilization by arthroscopic Bankart repair. Am J Sports Med 2011;39: 2147-2152.

23. Waters PM, Monica JT, Earp BE, Zurakowski D, Bae DS. Correlation of radiographic muscle cross-sectional area with glenohumeral deformity in children with brachial plexus birth palsy. J Bone Joint Surg Am 2009;91: 2367-2375.

24. Raz Y, Henseler JF, Kolk A, et al. Patterns of ageassociated degeneration differ in shoulder muscles. Front Aging Neurosci 2015;7:236.

25. von Heijne ASB, Dahlbom M, Jonsson U. Hill-Sachs' lesions and changes in the infraspinatus tendon: Assessment by MRI and MR arthrography. J Shoulder Elbow Surg 1996;5:531.

26. Funakoshi T, Hartzler RU, Stewien E, Burkhart SS. HillSachs lesion classification by the glenoid track paradigm in shoulder instability: Poor agreement between 3dimensional computed tomographic and arthroscopic methods. Arthroscopy 2019;35:1743-1749. 